\title{
Efficacy analysis of in situ synthesis of nanogold via copper/iodonium/amine/gold system under a visible light
}

\author{
Jui-Teng Lin ${ }^{1, *}$, Jacques Lalevee ${ }^{2}$, Haja Tar $^{3}$ and Da-Chun Cheng ${ }^{3, *}$
}

. ${ }^{1}$ New Vision Inc., 10F, No. 55, Sect.3, Xinbei Blvd, Xinzhuang, New Taipei City,

Taiwan;ROC; jtlin55@gmail.com

2 Université de Haute-Alsace, CNRS, IS2M UMR 7361, F-68100 Mulhouse, France; jacques.lalevee@uha.fr

${ }^{3}$ Department of Chemistry, Qassim University, Saudi Arabia; h.tar@qu.edu.sa

. ${ }^{4}$ Department of of Biomedical Imaging and Radiological Science, China Medical University, Taichung, Taiwan; ROC; dccheng@mail.cmu.edu.tw

*Correspondences: jtlin55@gmail.com; dccheng@mail.cmu.edu.tw

\begin{abstract}
This article presents, for the first time, the kinetics and the general features of a photopolymerization system (under visible light) G1/ Iodonium/ TEA/gold chloride (or A/B/N/G), having initial concentrations of $A_{0}, B_{0}$, No and $G_{0}$, based on the proposed mechanism of Tar et al. Analytic formulas are developed to explore the new features including: (i) both FRP efficacy and the production of nanogold (NG) are proportional to the relative concentration ratios of $\left(A_{0}+B_{0}+N_{0}\right) / G_{0}$, which may be optimized for maximum efficacy; (ii) the two competing procedure of NG production and efficacy of free radical photopolymerization (FRP) can be tailored for optimal system with nanogold in the polymer matrix;(ii) the FRP efficacy is contributed by 3 components: the coupling of the excited state of copper complex $(\mathrm{T})$ with the radicals (R and $\mathrm{S}$ ) produced by the iodonium and the amine; (iii) the production of NG is contributed by 2 components: the coupling of $\mathrm{T}$ and radical (S) with gold ion; (iv) NG production has a transient state value which is an increasing function of light intensity and the combined concentration ratio $\left[\left(\mathrm{A}_{0} / \mathrm{G}_{0}\right)+\left(\mathrm{N}_{0} /\left(\mathrm{K}^{\prime} \mathrm{M}_{0}\right)\right.\right.$. whereas it has a steady-state independent to the light intensity.
\end{abstract}

Keywords: polymerization kinetics; photoinitiator; free radical polymerization; copper complex, photoredox catalyst; nanogold particles.

\section{Introduction}

Light sources from UV (365 nm) to near-infrared $(980 \mathrm{~nm})$ have been used for photopolymerization reactions in many industrial and medical applications such as dental curing, microlithography, stereolithography, microelectronics, holography [1,2]. Photopolymerization using light sources from UV $(365 \mathrm{~nm})$ to near-infrared $(980 \mathrm{~nm})$ have been used in many industrial and medical applications such as dental curing, microlithography, stereolithography, microelectronics, holography [1,2]. Variety of photoresponsive materials such as conjugated polymers have been reported for additive manufacturing (AM) and recently for 3D and 4D bioprinting [3,4]. Both spatial and temporal controlled 3D processes were reported using single and multiple wavelength lights $[5,6]$. We have reported the kinetics and efficacy analysis for various strategies for improved conversion, such as co initiators, co additives in both single and multiple components systems [7-11]. 
Organic dyes used as visible light photosensitizers of polymerization have been extensively studied [12,13], in which high extinction coefficients and their long-living excited states, enabling the photosensitizers to react efficiently with various additives in the photocurable resins. For cost effective with long-living excited states, copper complexes have been used as a new polymerization approach enabling the formation of acetylacetonate radicals by redox reaction with a phosphine and to initiate the free radical polymerization (FRP) of acrylates or the free radical promoted cationic polymerization (CP) of epoxides [14-17]. Recently, Coumarin as dual function of photoinitiators in photo-oxidation or photo-reduction in visible light were reported [18-20]. The efficiency of copper complex (G1) based photoinitiating systems (G1/iodonium salt (Iod)/Nvinylcarbazole (NVK) was investigated by Mokbel et al [16] for free radical polymerization (FRP) of acrylates and the free radical promoted cationic polymerization $(\mathrm{CP})$ of epoxides using light source (LEDs at 375, 395, $405 \mathrm{~nm}$, halogen lamp).

More recently, our group also report the novel copper photoredox polymerization for in situ synthesis of metal nanoparticles, Tar et al [21].

This article will present, for the first time, the kinetics and the general features of a photopolymerization system (under visible light), Copper/ Iodonium/ TEA/gold chloride based on the proposed mechanism of Tar et al [21]. Analytic formulas will be developed to explore the new features. Finally, the measured data of Tar et al [19] will be quantitatively analyzed by our formulas, rather than their qualitative discussions.

\section{Methods and Modeling Systems}

\subsection{Photochemical Kinetics}

A specific measured system was reported by Tar et al [21], in which their proposed kinetic (shown in Scheme 1) for a 3-component system of G1/Iod/amine, where G1 is a copper complex $\mathrm{HLCuCl}$, amine can be TEA (itriethylamine), a reducing agents in the formation of gold nanoparticle inside the polymer matrix; and Iod is iodonium salt (oxidizing agent). The photoinitiating (PI) systems are mainly based on G1/TEA/Iodonium salt $(0.05 / 1 \% / 1 \% w / w)$ to the gold chloride $\left(\mathrm{HAuCl}_{4}\right)$ added $4 \mathrm{wt} \%$ in a few drops of DMF, and the PI system was dissolved in EGDA at $93.95 \mathrm{wt} \%$.

$\begin{array}{llll}\mathrm{Cu}+(\text { light }) & -> & \mathrm{Cu}^{*}(\text { excited state }) & (\mathrm{r} 1) \\ \mathrm{Cu}^{*}+\mathrm{Ar}_{2} \mathrm{I}(+) & \rightarrow & \mathrm{Cu}(+)+\mathrm{Ar}^{\circ}+\mathrm{ArI} & (\mathrm{r} 2) \\ \mathrm{Cu}^{*}+\text { amine } & \rightarrow & \mathrm{Cu}(-)+\operatorname{amine}\left({ }^{\circ}+\right) & (\mathrm{r} 3) \\ \mathrm{amine}^{\circ}\left({ }^{\circ}\right) & \rightarrow & \mathrm{amine}{ }^{\circ}+\mathrm{H}(+) & (\mathrm{r} 4) \\ \mathrm{Cu}^{*}+\mathrm{Au}(3+) & \rightarrow & \mathrm{Cu}(+)+\mathrm{Au}(2+) & (\mathrm{r} 5) \\ \mathrm{Cu}^{*}+\mathrm{Au}(2+) & \rightarrow & \mathrm{Cu}(+)+\mathrm{Au}(1+) & (\mathrm{r} 6) \\ \mathrm{Cu}^{*}+\mathrm{Au}(1+) & \rightarrow & \mathrm{Cu}(+)+\mathrm{Au}(0) & (\mathrm{r} 7) \\ \mathrm{amine}^{\circ}+\mathrm{Au}(3+) & \rightarrow & \mathrm{amine}(+)+\mathrm{Au}(2+) & (\mathrm{r} 8) \\ \mathrm{amine}^{\circ}+\mathrm{Au}(2+) & \rightarrow & \text { amine }(+)+\mathrm{Au}(1+) & (\mathrm{r} 9) \\ \text { amine }^{\circ}+\mathrm{Au}(1+) & \rightarrow & \text { amine }(+)+\mathrm{Au}(0) & (\mathrm{r} 10)\end{array}$

Scheme 1, A proposed kinetics for a 3-component system of G1/Iod/amine in gold chloride ( $\left.\mathrm{HAuCl}_{4}\right)$ solution, where $\mathrm{Cu}$ is for copper complex $(\mathrm{HLCuCl})$, having an excited state $\mathrm{Cu}^{*}$, which couples with iodonium salt, $\operatorname{Ar}_{2} \mathrm{I}(+)$, and amine to produce radicals, $\left(\mathrm{Ar}^{0}\right.$ and amine $\left.{ }^{0}\right)$ which lead to FRP. Both $\mathrm{Cu}^{*}$ and amine ${ }^{0}$ can couple with $\mathrm{Au}(3+)$ to form $\mathrm{Au}(2+)$, then $\mathrm{Au}(1+)$, leading to $\mathrm{Au}(0)$ and the nanogold [21].

The decomposition of the iodonium salt through an electron transfer and the production of a radical that is able to abstract hydrogen to generate radicals, which reduce the tetrachloroaurate $\mathrm{Au}^{+3}$ to form $\mathrm{Au}^{+2}$. then reduced to $\mathrm{Au}^{+1}$, and further to $\mathrm{Au}^{0}$, leading to the formation of nanogold (NG). The reduction of $\mathrm{HAuCl}_{4}$ occurs due to a transfer of electrons from the amine to the metal ion. The 
interaction of the G1, TEA and gold chloride was very fast, (within 60 s) under a visible light at 419 $\mathrm{nm}$. After five minutes under irradiation, the absorption of the complex and $\mathrm{Au}^{+3}$ have entirely disappeared having an increase in absorption at the green $(532 \mathrm{~nm})$, which corresponds the surface plasmon resonance (SPR) absorption [21-23]. The peak absorption (at $532 \mathrm{~nm}$ ) of nanogold (NG) in round shape moves toward near IR if the NG is in a bar shape (with a length ratio of 4.0) [24].

Using the short hand notations: $\mathrm{A}=$ copper complex, $\mathrm{T}=$ excited state, $[\mathrm{HLCuCl}]^{*}, \mathrm{~B}=\mathrm{Iod}$; $\mathrm{N}$ is triethylamine (TEA), $\mathrm{R}=[\mathrm{HLCuCl}]^{+*}, \mathrm{G}=\mathrm{Au}^{+3,}, \mathrm{G}^{\prime}=\mathrm{Au}^{+2}$ or $\mathrm{Au}^{+1}$. The monomer (M) is EGDA (for FRP conversion). The associated Chart for Scheme 1, is shown in Fig. 1. (only the key componets are shown). As shown by Figure 1, a 3-initiator system (A/B/N) defined by the ground state of initiatorA, which is excited to its first-excited state, and a triplet excited state $\mathrm{T}$ having a quantum yield (q). The triplet state $\mathrm{T}$ interacts with initiator [B] to regenerate $\mathrm{A}$, and produce a radical $\mathrm{R}$, or interacts with $\mathrm{N}$ to produce another radical S. Both radicals ( $R$ and $S$ ) can interact with the monomer $(M)$ for FRP. Furthermore, $T$ ad $R$ can interact with the gold $\left(G\right.$, or $\left.A u^{+3}\right)$ to produce exited-gold $\left(G^{\prime}\right.$, or $A u^{+2}$ and $\mathrm{Au}^{+1}$ ), which then further couples with $\mathrm{T}$ and $\mathrm{S}$ leading to the fromation of nanogold (NG, or $\left.\mathrm{Au}^{0}\right)$ in the polymer matrix. We note that Fig. 1 is more general than that of Scheme 6, because ot can be applied for different 3-component system, A/B/N, having various initiator (A), or additives (B and $\mathrm{N}$ ) and in various metal chlorid (such as gold and silver). The present article is focusing on the feature of NG production and limits to FRP. The general case with both FRP and CP was presneted elasewhere $[19,20]$.

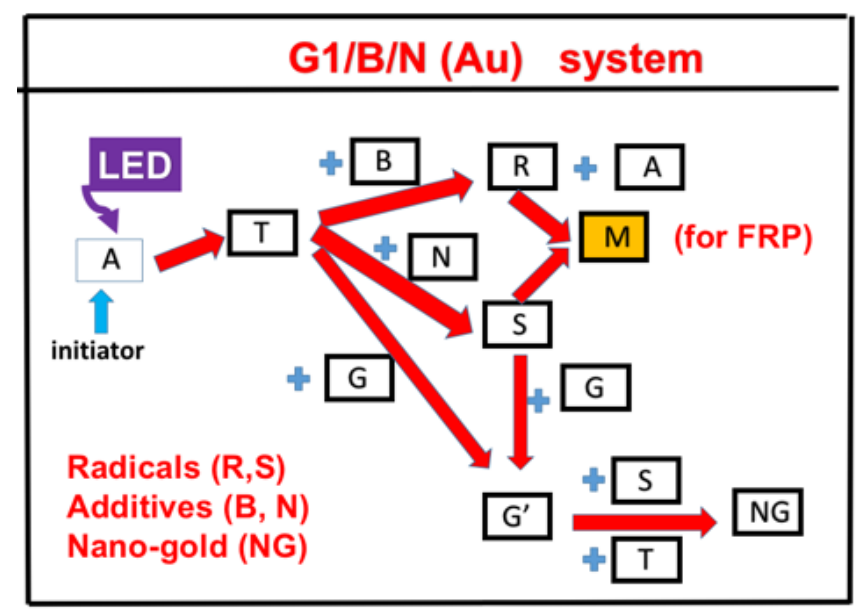

Figure 1. The schematics of a 3-component system, $(A / B / N)$, where $A$ is the ground state of initiator$A$, having an excited triplet state $T$, which interacts with additives $[B]$ and $[N\}$ to produce radicals $R$ and $S$, which can interact with the monomer (for FRP), or interact with the gold $\left(\mathrm{G}\right.$, or $\left.\mathrm{Au}^{+3}\right)$ to produce exitedgold $\left(\mathrm{G}^{\prime}\right.$, or $\mathrm{Au}^{+2}$ and $\left.\mathrm{Au}^{+1}\right)$, which then further couples with $\mathrm{T}$ and $\mathrm{S}$ leading to the formation of nanogold $\left(\mathrm{NG}\right.$, or $\left.\mathrm{Au}^{0}\right)$ in the polymer matrix.

The kinetic equations for the concentration of each components of the 3- components $(A / B / N)$ system (shown in Fig.1 and Scheme 1) are constructed as follows [19,25-27].

$\frac{d[A]}{d t}=-b I[A]\left(1-R_{E}\right)$

$\frac{d[B]}{d t}=-k_{1} T[B]$

$\frac{d N}{d t}=-k_{2} T[N]$

$\frac{d T}{d t}=b I[A]-\left(k_{7}+k_{1}[B]+k_{2}[N]+k_{3} G+k M\right) T$ 
$\frac{d R}{d t}=k_{1}[B] T-\left(k^{\prime} R+k^{\prime \prime} S+K M\right) R$

$\frac{d S}{d t}=k_{2}[N] T-\left(k_{4} G+k^{\prime \prime} R+K^{\prime} M\right) S$

$\frac{d G}{d t}=-\left(k_{3} T+k_{4} S\right) G$

$\frac{d G^{\prime}}{d t}=\left(k_{3} T+k_{4} S\right) G-\left(k_{5} T+k_{6} S\right) G^{\prime}$

In Eq. (1) $R_{E}$ is the regeneration (REG) term of of the initiator, $[A]$, given by $R_{E}=g\left(k_{7}+k_{1}[B]\right)$, with $g=\mathrm{k}_{7}+\mathrm{k}_{1}[\mathrm{~B}]+\mathrm{k}_{2}[\mathrm{~N}]+\mathrm{k}_{3} \mathrm{G} . \mathrm{b}=83.6 a^{\prime} w q$, where $w$ is the light wavelength (in $\mathrm{cm}$ ) and $q$ is the triplet state T quantum yield; $a^{\prime}$ is the mole absorption coefficient, in $(1 / \mathrm{mM} / \%)$ and $\mathrm{I}(\mathrm{z}, \mathrm{t})$ is the light intensity, in $\mathrm{mW} / \mathrm{cm}^{2}$. All the rate constants are defined previously [22] and they are related by the coupling terms. For examples, $k_{j}$ (with $j=1,2,3$ ) are for the couplings of $T$ and $[B],[N]$, and $G$, respectively; $\mathrm{K}$ is for the coupling radicals $\mathrm{R}$ with monomer $\mathrm{M}$ (for FRP). In above kinetics, we include the bimolecular termination [25] given by k'RR coupling in Eq. (5), but for analytic formulas, we will keep only the unimolecular coupling term, KM, for FRP.

The monomer conversions for FRP and generation of NG are given by [25]

$\frac{d M}{d t}=-\left(k T+K R+K^{\prime} S\right) M$

$\frac{d[N G]}{d t}=\left(k_{5} T+k_{6} S\right) G^{\prime}$

For comprehensive modeling we will use the so-called quasi-steady state assumption [25-27]. The life time of the singlet and triplet states of photosensitizer, the triplet state $(\mathrm{T})$, and the radicals $\left(R, S^{\prime}\right.$ and $\left.S\right)$, since they either decay or react with cellular matrix immediately after they are created. Thus, one may set $\mathrm{dT} / \mathrm{dt}=\mathrm{dR} / \mathrm{dt}=\mathrm{dS} / \mathrm{dt}=\mathrm{dG} / \mathrm{dt}=0$, which give the quasi-steady-state solutions: $\left.\left.\mathrm{T}=\mathrm{bIg}[\mathrm{A}], \mathrm{R}=\mathrm{k}_{1} \mathrm{bIgg}^{\prime}[\mathrm{A}][\mathrm{B}]\right), \mathrm{S}=\mathrm{k}_{2} \mathrm{bIgg}^{\prime}[\mathrm{A}][\mathrm{N}]\right), \mathrm{G}^{\prime}=\left(\mathrm{k}_{3} \mathrm{~T}+\mathrm{k}_{4} \mathrm{~S}\right) /\left(\mathrm{k}_{5} \mathrm{~T}+\mathrm{k}_{6} \mathrm{~S}\right) ;$ with $\mathrm{g}=1 /\left(\mathrm{k}_{7}+\mathrm{k}_{1}[\mathrm{~B}]+\mathrm{k}_{2}[\mathrm{~N}]+\right.$ $\left.\mathrm{k}_{3} \mathrm{G}+\mathrm{kM}\right), \mathrm{g}^{\prime}=1 /\left(\mathrm{k}^{\prime \prime} \mathrm{S}+\mathrm{KM}\right), \mathrm{g}^{\prime \prime}=1 /\left(\mathrm{k}_{4} \mathrm{G}+\mathrm{k} " \mathrm{R}+\mathrm{K}^{\prime} \mathrm{M}\right)$.

Under the above quasi-steady-state solutions, we obtain the simplified equations as follows.

$\frac{d[A]}{d t}=-b I[A]\left(1-R_{E}\right)$

$\frac{d[B]}{d t}=-k_{1} \operatorname{bIg}[A][B]$

$\frac{d N}{d t}=-k_{2} b \operatorname{Ig}[A][N]$

$\frac{d G}{d t}=-b I g[A]\left(k_{3}+k_{2} g^{\prime \prime}[N]\right) G$

The monomer conversions for FRP and generation of NG are given by [26]

$\frac{d M}{d t}=-b \operatorname{Ig}[A]\left(k+k_{1} K g^{\prime}[B]+k_{2} K^{\prime} g^{\prime \prime}[N]\right) M$

$\frac{d[N G]}{d t}=\operatorname{bIg}[A]\left(k_{5}+k_{6} k_{2} g^{\prime \prime}[N]\right)$

\section{3.. Results and discussion}

A full numerical simulation is required for the solutions of Eq. (11)-(16), which will be presenetd elasewhere. We will focus on comprehensive analysis for special features and the key factors for 
efficient producing of NG related to the measured data of Tar et al [22], based on the analytic formulas.

\subsection{Analytic results}

Analytic formulas need assumption of strong coupling of $\mathrm{T}$ and [B], and $\mathrm{KM}>>\mathrm{k}^{\prime \prime} \mathrm{S}, \mathrm{K}{ }^{\prime} \mathrm{M}>>\mathrm{k}_{4} \mathrm{G}$ such that $g=1 /\left(k_{3} G\right), g^{\prime}=1 /(K M)$, and $g^{\prime \prime}=1 /\left(K^{\prime} M\right)$. Also $R_{E}$ is taken as a mean reduction factor $\left(f^{\prime}\right)$, such that $\left(1-R_{E}\right)=f^{\prime}=\left[1-k_{2} N_{0} /\left(k_{3} G_{0}\right)\right]$ is time independent having a value of $f^{\prime}=0.5$ to 1.0 . The first-order solutions of Eq. (11) to (15) are found: $[\mathrm{A}]=\mathrm{A}_{0} \exp (-\mathrm{dt})$; with $\mathrm{d}=\mathrm{f}^{\prime} \mathrm{bI} ;[\mathrm{B}]=\mathrm{B}_{0} \exp (-\mathrm{H})$, with $\mathrm{H}(\mathrm{t})=\mathrm{DE}(\mathrm{t})$, with $\mathrm{E}(\mathrm{t})=[1-\exp (-\mathrm{dt})] / \mathrm{d}] ;[\mathrm{N}]=\mathrm{N}_{0} \exp \left(-\mathrm{H}^{\prime}\right), \mathrm{H}^{\prime}=\mathrm{D}^{\prime}\left(\mathrm{k}_{2} / \mathrm{k}_{1}\right) \mathrm{D}$, with $\mathrm{D}=\left(\mathrm{k}_{1} / \mathrm{k}_{3}\right) \mathrm{d}\left(\mathrm{A}_{0} / \mathrm{G}_{0}\right)$. Also $\mathrm{G}(\mathrm{t})=\mathrm{G}_{0}-$ $\left(\mathrm{k}_{1} / \mathrm{k}_{3}\right) \mathrm{dt} ; \mathrm{G}^{\prime}=\left(\mathrm{k}_{3} / \mathrm{k}_{5}\right)\left[1+\mathrm{k}_{4} \mathrm{~S} / \mathrm{T}\right]=\left(\mathrm{k}_{3} / \mathrm{k}_{5}\right)\left[1+\mathrm{k}_{4}[\mathrm{~N}] /(\mathrm{KM})\right.$, for $\mathrm{k}_{5} \mathrm{~T}>\mathrm{k}_{6} \mathrm{~S}$. Using these approximated solutions, Eq. (15) and (16) become

$$
\begin{aligned}
& \frac{d M}{d t}=-k F(t) M-F\left(k_{1}[B\}+k_{2}[N]\right) \\
& \frac{d[N G]}{d t}=F(t)\left(k_{5}+k_{6} k_{2}[N] /\left(K^{\prime} M\right)\right) G^{\prime}
\end{aligned}
$$

where $F^{\prime}(t)=b I[A]\left(k_{3} G\right)$.

Sovling for Eq. (17), we obtain the first-order solution, with $G(t)=G_{0}$, and $G^{\prime}=\left(k_{3} / k_{5}\right)$.

$$
\mathrm{M}=\mathrm{M}_{0} \exp [-\mathrm{P}(\mathrm{t})]+\mathrm{Ho}(\mathrm{t})
$$

where $\mathrm{P}(\mathrm{t})=\mathrm{Q}[1-\exp (-\mathrm{dt})] / \mathrm{d}]$; with $\mathrm{Q}=\left(\mathrm{k} / \mathrm{k}_{3}\right) \mathrm{bI}\left(\mathrm{A}_{0} / \mathrm{G}_{0}\right)$; and $\mathrm{Ho}(\mathrm{t})$ is a complex second order term proprotional to $\mathrm{bIA}_{0}\left(\mathrm{k}_{1} \mathrm{~B}_{0}+\mathrm{k}_{2} \mathrm{~N}_{0} / \mathrm{B}_{0}\right) / \mathrm{G}_{0}$. We note that $\mathrm{P}(\mathrm{t})$ has a transient state value $\mathrm{P}=\mathrm{Qt}$, and steady-state value, $\mathrm{P}=\mathrm{Q} / \mathrm{d}$, which is independnet to the light intensity.

Production of nanogold, [NG], is given by the solution of Eq. (18),

$$
[N G](t)=D^{\prime}\left[E(t)+Q^{\prime} E^{\prime}(t)\right]
$$

where $\left.Q^{\prime}=\left(k_{6} k_{2} / k_{3}\right)\left(N_{0} /\left(K^{\prime} M_{0}\right), E(t)=[1-\exp (-d t)] / d\right] ; E^{\prime}(t)=\left[1-\exp \left(-d^{\prime} t\right)\right] / d^{\prime}\right] ; D^{\prime}=b I\left(A_{0} / G_{0}\right) ; d^{\prime}=$ $\mathrm{d}+\left(\mathrm{k}_{1} / \mathrm{k}_{3}\right) \mathrm{D}, \mathrm{D}=\left(\mathrm{k}_{1} / \mathrm{k}_{3}\right) \mathrm{d}\left(\mathrm{A}_{0} / \mathrm{G}_{0}\right)$. We note that $[\mathrm{NG}](\mathrm{t})$ has a transient state value $[\mathrm{NG}]=\mathrm{D}^{\prime}\left(1+\mathrm{Q}^{\prime} \mathrm{t}\right)$; and steady-state value, $[N G]=D^{\prime}\left(1 / d+Q^{\prime} / d^{\prime}\right)$, which is independent to the light intensity.

\subsection{General features and new findings}

As shown by Eqs. (17) to (20), the following significant features of the A/B/N/Gold, or $\mathrm{Cu} / \mathrm{Iod} /$ Amine/Gold, system are summarized as follows (referred also to Scheme 1, and Fig. 1).

(i) The additive [B], or Iod (an oxidizing agent) interacts with copper exicited state $\left(\mathrm{T}\right.$, or $\left.\mathrm{Cu}^{*}\right)$ to produce radical $(\mathrm{R})$ and also to regenerate the initiator, $[\mathrm{A}]$ (or $\mathrm{Cu}$ ), shown by $\mathrm{R}_{\mathrm{E}}=\mathrm{g}\left(\mathrm{k}_{7}+\mathrm{k}_{1}[\mathrm{~B}]\right)$ term in Eq.(11).

(ii) The additive, [N] (or amine), has dual functions: interacting with $\mathrm{T}$ to produce additional radical $\left(S\right.$, or amine ${ }^{0}$ ) which leads to FRP; and coupled with $G$, or $\mathrm{Au}(3+)$, to form $\mathrm{Au}(2+)$, then $\mathrm{G}^{\prime}$, or $\mathrm{Au}(1+)$, leading to $\mathrm{Au}(0)$ and the nanogold (NG).

(iii) Eq. (9) and (17) show that the FRP is contributed by 3 components: from the coupling of monomer $(\mathrm{M})$ with $\mathrm{T}, \mathrm{R}$, and $\mathrm{S}$. The conversion efficacy is proportional to $\mathrm{bI}\left(\mathrm{A}_{0}+k_{1} \mathrm{~B}_{0}+k_{2} \mathrm{~N}_{0}\right) /\left(\mathrm{k}_{3} \mathrm{G}_{0}\right)$. which is an increasing function of he absorption coefficient (b) and light intensity (I), and the concentration ratios of $\left(\mathrm{A}_{0}+\mathrm{B}_{0}+\mathrm{N}_{0}\right) \mathrm{G}_{0}$.

(iv) Eq. (10) and (18) show that the production of NG is contributed by 2 components: from the coupling term of $\left(\mathrm{k}_{5} \mathrm{~T}+\mathrm{k}_{6} \mathrm{~S}\right) \mathrm{G}^{\prime}$ shown by Eq. (10). In addition, as shown by Eq. (20), [NG](t) has a 
transient state value $[N G]=D^{\prime}\left(1+Q^{\prime}\right) t$, which is an increasing function of bI $\left[\left(\mathrm{A}_{0} / \mathrm{G}_{0}\right)+\left(\mathrm{N}_{0} /\left(\mathrm{K}^{\prime} \mathrm{M}_{0}\right)\right.\right.$; and the steady-state value, $[N G]=D^{\prime}\left(1 / d+Q^{\prime} / d\right)$, which is independent to the light intensity.

Besides the above described features, our modeling has explored the follow new findings which are not observed in the experiment of Tar et al \{\} .

(a) Both FRP efficacy and the production of NG are proportional to the relative concentration ratios of $\left(\mathrm{A}_{0}+\mathrm{B}_{0}+\mathrm{N}_{0}\right) / \mathrm{G}_{0}$, rather than the individual concentrations. Therefore, photoinitiating system reported by Tar et al [ $\}$ based on G1/TEA/Iodonium, having $(0.05 / 1 \% / 1 \% \mathrm{wt})$ and $4 \mathrm{wt} \%$ of gold chlorid $\left(\mathrm{G}_{0}\right.$, or $\left.\mathrm{HAuCl}_{4}\right)$, is not optimized. Our modeling predicts that lower initial gold chlorid $\left(\mathrm{G}_{0}\right)$ and/or larger $\left(\mathrm{A}_{0}+\mathrm{B}_{0}+\mathrm{N}_{0}\right)$, leads to higher ratio of $\left(\mathrm{A}_{0}+\mathrm{B}_{0}+\mathrm{N}_{0}\right) / \mathrm{G}_{0}$, and therefore higher FRP and larger production of NG. It seems that Tar et al [ \} have used a too high gold, but too low G1 ocncentration. In addition, our formula of Eq. (19) predicts an optimal value of the concentration ratio $\left(\mathrm{A}_{0}+\mathrm{B}_{0}+\mathrm{N}_{0}\right) / \mathrm{G}_{0}$, as also predicted by our previous modeling in other systems [ ].

(b) We note that [B] plays no role in the prodcution of NG under the firt-order solution, but plays minior role reducing the NG production, as shown by our second-order factor $\mathrm{g}=\left(1-\mathrm{k}_{1}[\mathrm{~B}] / \mathrm{G}-\right.$ $\left.\mathrm{k}_{2}[\mathrm{~N}] / \mathrm{G}\right) /\left(\mathrm{k}_{3} \mathrm{G}\right)$. Furthermore, there is a reduction effect of FRP efficacy due to the production of NG caused by the reduction of excited state $(\mathrm{T})$, when it couples with gold, $\mathrm{Au}(+3)$. On the other hand, higher FRP (or larger K'M term) also reduces the efficacy of NG production, as shown by the factor $\mathrm{Q}^{\prime}=\left(\mathrm{k}_{6} \mathrm{k}_{2} / \mathrm{k}_{3}\right)\left(\mathrm{N}_{0} /\left(\mathrm{K}^{\prime} \mathrm{M}_{0}\right)\right.$ in Eq. (20). Therefore, one may tailer the ratio of $\left(\mathrm{A}_{0}, \mathrm{~B}_{0}, \mathrm{~N}_{0}\right) / \mathrm{G}_{0}$ to achieve maxium NG production, but also the strength of polymer matrix (or higher FRP), which is a competing procedure of NG production.

\section{Conclusion}

We have presented, for the first time, the kinetics and the general features of a G1/ Iodonium/ TEA/gold chlorid (or A/B/N/G) system, based on proposed mechanism of Tar et al [19]. Analytic formulas are developed to explore the new features including: (i) the FRP efficacy is contributed by 3 components: the coupling of the excited state of copper complex (T) with the radicals (R and S) produced by the iodomium and the amine; (ii) the production of NG is contributed by 2 components: the coupling of $\mathrm{T}$ and radical (S) with gold ion; (iii) NG prodcution has a transient state value which is an increasing function of light intenisty and the commbined concentration ratio $\left[\left(\mathrm{A}_{0} / \mathrm{G}_{0}\right)+\left(\mathrm{N}_{0} /\left(\mathrm{K}^{\prime} \mathrm{M}_{0}\right)\right.\right.$. whereas it has a steady-state independent to the light intensity; (iv) both FRP efficacy and the production of NG are proportional to the relative concentration ratios of $\left(\mathrm{A}_{0}+\mathrm{B}_{0}+\mathrm{N}_{0}\right) / \mathrm{G}_{0}$, which may be optimized for maximum efficacy; and finally (v) the two competing procedure of NG production and efficacy of FRP can be tailered for optimal system with nonagold in the polymer matrix;

Funding: The Agence Nationale de la Recherche (ANR agency) is acknowledged for its financial support through the NoPerox grant.

Acknowledgments: JTL thanks the internal grant of New Vision Inc. and DCC thanks the financial support from 359 China Medical University with the grant number CMU109-S-39.

Conflicts of Interest: Jui-Teng Lin is the CEO of New Vision Inc.

\section{References}

1. Fouassier, J. P. \& Lalevée, J. Photoinitiators for Polymer Synthesis-Scope, Reactivity and Efficiency. Wiley-VCH Verlag GmbH \& Co. KGaA: Weinheim, Germany, 2012.

2. Yagci, Y., Jockusch, S. \& Turro, N.J. Photoinitiated polymerization: Advances, challenges and opportunities. Macromolecules 43, 6245-6260 (2010). 
3. Ligon, S.C.; Liska, R.; Stampfl, J.; Gurr, M.; Mulhaupt, R. Polymers for 3D printing and customized additive manufacturing. Chem. Rev. 2017, 117, 10212-10290.

4. Kelly, B.E.; Bhattacharya, I.; Heidari, H.; Shusteff, M.; Spadaccini, C.M.; Taylor, H.K. Volumetric Additive Manufacturing via Tomographic Reconstruction. Science 2019, 363, 1075-1079.

5. de Beer, M.P.; van der Laan, H.L.; Cole, M.A.; Whelan, R.J.; Burns, M.A.; Scott, T.F. Rapid, Continuous Additive Manufacturing by Volumetric Polymerization Inhibition Patterning. Sci. Adv. 2019, 5, 8.

6. van der Laan, H.L.; Burns, M.A.; Scott, T.F. Volumetric Photopolymerization Confinement through Dual-Wavelength Photoinitiation and Photoinhibition. ACS Macro Lett. 2019, 8, 899-904.

7. Lin J.T.; Chen K.T.; Cheng D.C.; Liu, H,W. Dual-wavelength (UV and Blue) controlled photopolymerization confinement for 3D-printing: modeling and analysis of measurements. Polymers, 2019, 11, 1819.

8. Lin, J.T.; Liu, H.W.; Chen, K.T.; Cheng, D..C. 3-wavelength (UV, blue, red) controlled photopolymerization: improved conversion and confinement in 3D-printing. IEEE Access, 2020, 8, 49353-49362.

9. Lin, J.T,; Lalevee, L.; Cheng. D,C. Synergetic kinetics of free radical and cationic photopolymerization in three co-initiators and two-monomers system. Polymers (2021, in press).

10. Lin, J.T.; Chen, K.T.; Cheng D.C.; Liu, H,W. Enhancing blue-light-initiated photopolymerization in a three-component system: kinetic and modeling of conversion strategies. J Polymer Research, 2021, 28:2.

11. Lin J.T.; Liu HW,; Chen KT,; Chiu YC, ; Cheng DC. Enhancing UV photopolymerization by a red-light pre-irradiation: kinetics and modeling strategies for reduced oxygeninhibition. J Polymer Science, 2020，58， 683-691， DOI:10.1002/pol.20190201.

12. Dietlin, C.; Schweizer, S.; Xiao, P.; Zhang, J.; Morlet-Savary, F.; Graff, B.; Fouassier, J.-P.; Lalevée, J. Photopolymerization upon LEDs: New Photoinitiating Systems and Strategies. Polym. Chem. 2015, 6, 3895-3912. [CrossRef]

13. Pigot, C.; Noirbent, G.; Brunel, D.; Dumur, F. Recent advances on push-pull organic dyes as visible light photoinitiators of polymerization. Eur. Polym. J. 2020, 133, 109797.

14. Garra, P.; Dietlin, C.; Morlet-Savary, F.; Dumur, F.; et al Redox two-component initiated free radical and cationic polymerizations: Concepts, reactions and applications. Progress in Polymer Science, 2019, 94, pp.33-56. 10.1016/j.progpolymsci.2019.04.003

15. Noirbent, G.; Dumur, F. Recent Advances on Copper Complexes as Visible Light Photoinitiators and (Photo) Redox Initiators of Polymerization. Catalysts, MDPI, 2020, 10, 10.3390/catal10090953.

16. Mokbel, H.; Anderson, D.; Plenderleith, R.; Dietlin, C.; et al. Simultaneous initiation of radical and cationic polymerization reactions using the "G1" copper complex as 
photoredox catalyst: Applications of free radical/cationic hybrid photopolymerization in the composites and 3D printingfields. Prog. Org. Coat., 132, 50-61 (2019). DOI: 10.1016/j.porgcoat.2019.02.044

17. Rahal, M.; Mokbel, H.; Graff, B.; Toufaily, J.; Hamieh, T.; Dumur, F.; Lalevée, J. Mono vs. Difunctional Coumarin as Photoinitiators in Photocomposite Synthesis and 3D Printing. Catalyst 2020, 10, 1202. [CrossRef]

18. Rahal, M.; Mokbel, H.; Graff, B.; Toufaily, J.; et al. 3-Carboxylic Acid and FormylDerived Coumarins as Photoinitiators in Photo-Oxidation or Photo-Reduction Processes for Photopolymerization upon Visible Light: Photocomposite Synthesis and 3D Printing Applications. Molecules 2021, 26, 1753. https://doi.org/ 10.3390/molecules26061753.

19. Lin, J.T.; Lalevee, J.; Cheng, D.C. Kinetics analysis of copper complex photoredox catalyst: roles of oxygen, thickness, and optimal concentration for radical/cationic hybrid photopolymerization. Polymers (2021, in press).

20. Abdallah, A.; Hijazi,A.; Lin, J.T.; Graff, B.; Dumur, F.; Lalevee, J. Coumarin Derivatives as Photoinitiators in Photo-Oxidation and Photo-Reduction Processes and a Kinetic Model for Simulations of the Associated Polymerization Profiles. App Polymer Material. 2020, 2,2769-2780.

21. Tar, H.; Kashar, T.I.; Kouki, N. et al. Novel Copper Photoredox Catalysts for Polymerization: An In Situ Synthesis of Metal Nanoparticles. Polymers 2020, 12, 2293; doi:10.3390/polym12102293.

22. Lin, J.T. Modeling the scaling law of surface plasmon resonance in gold spherical nanoshells. J. Nanophotonics 2010; 4:049507.

23. Lin JT. Nonlinear optical theory and figure of merit of surface plasmon resonance of gold nanorods, J. Nanophotonics 2011; 5:051506.

24. Lin JT. Scaling law and figure of merit of biosensor using gold nanoshells. J Nanophotonics, 2010;4: 049507.

25. Lin, J.T,; Cheng, D.C. Modeling the efficacy profiles of UV-light activated corneal collagen crosslinking. PloS One. 2017;12:e0175002.

26. Lin, J.T. Kinetics of enhancement for corneal cross-linking: proposed model for a twoinitiator system. Ophthalmology Research, 2019, 10(3): 1-6; Article no.OR.49970 DOI: 10.9734/OR/2019/v10i330109.

27. Lin, J.T,; Chen. K.T,; Cheng. D,C,; Liu. H,W. Modeling the efficacy of radical-mediated photopolymerization: the role of oxygen inhibition, viscosity and induction time. Front. Chem. 2019, 7:760. doi: 10.3389/fchem.2019.00760. 